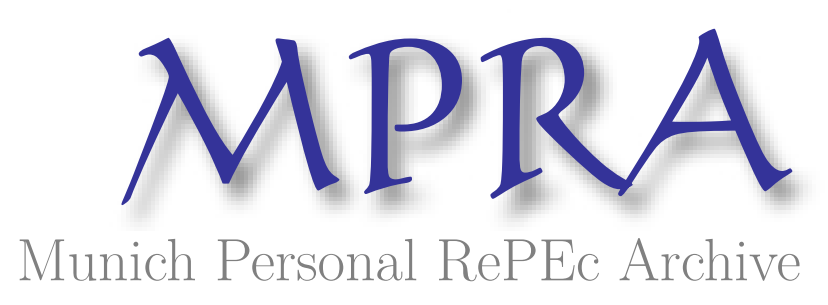

Natural Gas and U.S. Economic Activity

Arora, Vipin and Lieskovsky, Jozef

November 2012

Online at https://mpra.ub.uni-muenchen.de/42659/

MPRA Paper No. 42659, posted 18 Nov 2012 13:52 UTC 


\title{
NATURAL GAS AND U.S. ECONOMIC ACTIVITY*
}

\author{
Vipin Arora \\ U.S. Energy Information Administration
}

\author{
Jozef Lieskovsky \\ U.S. Energy Information Administration
}

\begin{abstract}
Previous empirical work has shown that real natural gas prices have a small to negligible impact on total U.S. industrial production and most of its sub-indices. We first show that these results still hold with a sample that runs through mid-2012 and uses a different natural gas price. Concerns about the joint determination of the real natural gas price and U.S. economic activity lead us to reassess these results using a multivariate framework. Our model shows that natural gas does affect U.S. economic activity, but primarily through changes in natural gas production. We also show that natural gas supply, inventory demand, and responses to events in the oil market have been the most important contributors to the real natural gas price since 2000 . In terms of approximate point estimates, our results indicate that increases in natural gas supply can raise total U.S. industrial production by 0.1 to 0.5 percent under plausible scenarios.
\end{abstract}

JEL Classification: E37, F47, Q43.

Keywords: Natural gas, VAR, Granger causality, endogenous, industrial production

\section{Introduction}

Relative to crude oil, comparatively little is known about the impact of the natural gas market on U.S. economic performance. This has become an important issue given recent dynamics in natural gas prices and production. Optimists continually tout the realized and potential economic benefits of the "shale-gas revolution", while many others remain unconvinced about its importance or magnitude. Implicit in either view is an assumption about the past and future macroeconomic impacts of the U.S. natural gas market, but the empirical work on which to base this assumption is relatively sparse.

In this paper we evaluate the importance of the natural gas industry on U.S. macroeconomic performance. Our primary goal is to provide an empirical basis on which to judge the possible impacts of recent developments in the U.S. natural gas market. We also seek to highlight the importance of a point made by Barsky and Kilian (2004), namely that supply and demand shocks in this market must be identified before any macroeconomic impacts can be quantified.

\footnotetext{
${ }^{*}$ The analysis and conclusions expressed here are those of the authors and not necessarily those of the U.S. Energy Information Administration.

${ }^{\dagger}$ We have benefitted from the comments and suggestions of Alan Beamon, John Conti, David Daniels, Thomas Lee, Elizabeth Sendich, Kay Smith, and Russell Tarver.
} 
We begin by assessing the impact of changes in real natural gas prices on total U.S. industrial production and various sub-indices. As with previous work by Kliesen (2006), we find no impact of past real natural gas prices on total industrial production, and only three industries where changes in real natural gas prices are able to forecast changes in production. While useful, the problem with these tests is that they do not take into account the fact that the real natural gas price is jointly determined with measures of economic activity. That is, while macroeconomic aggregates such as industrial production may change due to variations in natural gas prices, these aggregates can also alter the natural gas price itself. This reverse causality means that cause and effect are not well defined (Kilian, 2009).

To overcome this limitation we next estimate a structural vector autoregression (VAR) on monthly data and identify the relevant supply and demand shocks in the U.S. natural gas market using a recursive identification scheme. The four variables in our VAR characterize the supply, demand, and price of U.S. natural gas. These variables include the change in U.S. marketed natural gas production, U.S. natural gas demand for use in the production of goods, U.S. natural gas demand for heating and power generation, and the real wellhead price of U.S. natural gas. We also use a version of the model where the natural gas demand for the production of goods is replaced by total U.S. industrial production.

Associated with these variables are four shocks. The first is a natural gas supply shock, which captures unexpected changes in natural gas production. The second shock represents changes in the demand for natural gas for use in the production of goods. This is roughly similar to the aggregate demand shock of Kilian (2009), and we term this a goods production shock. This shock has the same interpretation when total U.S. industrial production is used in the VAR, as industrial production is a proxy for goods demand. The third shock, an energy demand shock, is associated with unexpected demand for natural gas for use in heating or power generation. The final shock in our model captures both inventory demand and the impact of events in the oil market. This is an other natural gas shock.

We assume that the natural gas supply shock can impact all variables in the model during the current month. The other three shocks are unable to change natural gas production in that same month, due to the associated difficulties and costs. The goods demand shock can impact energy demand and the real natural gas price. This is because changes in production demand due to economic activity may also be associated with changes in energy demand and movements in the real natural gas price. Similarly, the energy demand shock can vary the real natural gas price in the current month.

Given this identification scheme, we estimate our initial four-variable VAR over the period 1993M01-2012M05. In this version we use the direct measure of natural gas demand for use in production, and focus on the real natural gas price. Historical decompositions of this price lead to two conclusions. The first is that the factors driving the real natural gas price vary over time. The second point is that supply and other shocks have contributed more to the price in terms of magnitude then goods or energy demand shocks, especially post-2000. Impulse responses of the real natural gas price show that a rise in any of the shocks can have an impact on the price. However, only the supply and other shocks lead to an instantaneous impact on this price. In the case of the other shock, the real natural gas price immediately jumps over $9 \%$, while the supply shock leads to an instantaneous fall in the price of over $2 \%$.

We then replace our direct measure of natural gas demand for use in goods production with 
total U.S. industrial production and re-estimate the VAR over the same time period. The impulse responses and variance decomposition of industrial production imply that the supply of natural gas and demand for use in production are the two primary channels by which natural gas affects economic activity. In contrast, neither energy demand or other shocks seem to have an impact on economic activity.

In terms of point estimates, the VAR results show that a $1 \%$ increase in natural gas production leads to an immediate $0.1 \%$ rise in U.S. industrial production. The average monthly increase (from the same month in the previous year) in marketed U.S. natural gas production has been $0.6 \%$ since 1976, $1.5 \%$ since $1993,3.5 \%$ since 2005 , and $4.3 \%$ since 2007 . Within a plausible range of natural gas production estimates, our results indicate that increases in natural gas supply alone might raise monthly industrial production by 0.1 to 0.5 percent. Our conclusion is that the natural gas market does impact U.S. economic activity, and the primary channel for this effect is through variations in natural gas supply.

\section{Stylized Facts}

In 2011 natural gas was the source of almost $25 \%$ of U.S. energy consumption according to the Energy Information Administration (EIA), making it the second-largest primary source of energy behind petroleum. ${ }^{1}$ Figure 1, taken from the EIA's Annual Energy Review (AER) 2011, shows the importance of primary energy sources to different U.S. end-use sectors. ${ }^{2}$

The fact that petroleum is the largest primary energy source clearly stands out in Figure 1, as does the distribution of primary energy use. Over $71 \%$ of petroleum is used in the transportation sector, and this petroleum meets $93 \%$ of the demand for energy in transportation. Interestingly, the share of industrial energy demand provided by natural gas and petroleum is almost the same. Petroleum accounts for $40 \%$ of this sector's primary energy consumption, whereas natural gas accounts for $41 \%$. However, a third of natural gas used in the U.S. economy is used in the industrial sector, while only $23 \%$ of oil is used in this sector.

Natural gas provides three quarters of the primary energy used in the residential and commercial sector. And natural gas accounts for about a fifth of electric power primary energy consumption. Demand from the residential and commercial and electric power sectors each account for about a third of natural gas used in the U.S. economy. Overall, Figure 1 shows that the use of natural gas as an energy source is spread out between end-use sectors.

\subsection{Natural Gas use in Industry}

The importance of natural gas for use in the industrial, residential and commercial, and electric power end-use sectors suggests that it may impact U.S. economic activity through the supply-side of the economy. Table 1 looks closer at different industrial sectors of the economy in relation to

\footnotetext{
${ }^{1}$ EIA defines primary energy as: Energy in the form that it is first accounted for in a statistical energy balance, before any transformation to secondary or tertiary forms of energy.

${ }^{2}$ EIA defines an end-user as: A firm or individual that purchases products for its own consumption and not for resale (i.e., an ultimate consumer).
} 
natural gas. ${ }^{3}$

\begin{tabular}{lccc}
\hline & NG Share GO & Industry Share GO & NG Share of Energy \\
\hline Nonmetallic Mineral Products & $29.21 \%$ & $0.48 \%$ & $41.29 \%$ \\
Paper & $27.69 \%$ & $0.76 \%$ & $20.14 \%$ \\
Primary Metals & $21.54 \%$ & $0.86 \%$ & $36.12 \%$ \\
Food, Beverage, and Tobacco & $10.18 \%$ & $2.99 \%$ & $52.51 \%$ \\
Textiles and Products & $9.49 \%$ & $0.35 \%$ & $44.40 \%$ \\
Chemicals & $9.06 \%$ & $2.45 \%$ & $33.91 \%$ \\
Apparel and Leather Goods & $8.56 \%$ & $0.22 \%$ & $47.06 \%$ \\
Wood Products & $7.60 \%$ & $0.44 \%$ & $19.29 \%$ \\
Fabricated Metal Products & $6.61 \%$ & $1.30 \%$ & $60.61 \%$ \\
Printing and Related Activities & $5.28 \%$ & $0.48 \%$ & $45.88 \%$ \\
Plastics and Rubber Products & $5.27 \%$ & $0.85 \%$ & $37.98 \%$ \\
Petroleum and Coal Products & $4.56 \%$ & $1.66 \%$ & $12.37 \%$ \\
Furniture and Related Products & $3.23 \%$ & $0.35 \%$ & $27.87 \%$ \\
Electrical Equipment and Related & $3.17 \%$ & $0.53 \%$ & $40.78 \%$ \\
Machinery & $2.74 \%$ & $1.34 \%$ & $41.18 \%$ \\
Miscellaneous & $2.24 \%$ & $0.62 \%$ & $37.88 \%$ \\
Computer and Electronic Products & $1.78 \%$ & $1.92 \%$ & $31.69 \%$ \\
\hline
\end{tabular}

Table 1: Shares of Listed Variables in Select Industries

The first column of Table 1 lists the average share of expenditures on natural gas relative to gross output in each sector since 1998, which is when the data become available. This gives a sense of how important natural gas is as an input to production in relation to total production for each sector. The use of natural gas in these industries varies substantially, as it accounts for almost $30 \%$ of gross output in the nonmetallic minerals sector but less than $2 \%$ of gross output in the computer and electronics sector.

While this highlights the relative importance of natural gas in each of these sectors, the second column of Table 1 shows the relative importance of each sector in national gross output on average since 1998. For example, even though natural gas is an important input to the nonmetallic minerals sector, this sector is a relatively small part of U.S. gross output, accounting for about $0.5 \%$ on average since 1998. The two largest industrial sectors are food, beverages, and tobacco and chemicals, accounting for around $3 \%$ and $2.5 \%$ of U.S. gross output on average since 1998 .

The final column of Table 1 lists the share of natural gas used as a fraction of total energy consumption in the various sectors. ${ }^{4}$ This column shows that even in the industries which spend relatively little on natural gas, it still accounts for at least $20 \%$ of energy consumption (the only exception is petroleum and coal products).

\subsection{Natural Gas use in Consumption}

Nearly $70 \%$ of natural gas is used outside of the industrial sector. Potentially, variations in natural gas prices can impact consumers through these other sectors by altering their expenditures on energy and energy-related goods. This can happen by changing disposable income, by increasing

\footnotetext{
${ }^{3}$ See the appendix for details on calculations and data sources. These industrial sectors cover the major three digit NAICS codes from 31-33.

${ }^{4}$ This includes natural gas used in the production of electricity, which is subsequently used in each sector.
} 
precautionary savings in the case of a price rise, or by causing consumers to change their plans for the purchases of durable goods (Kilian, 2008).

These consumer responses become clearer when examining the share of consumer income spent on different energy products. Table 2 shows the average share of personal consumption expenditures (PCE) spent on natural gas (primarily for heating), electricity, fuel oil (primarily for heating), and motor vehicle fuels over two different sample periods. ${ }^{5}$ The spending on oil-related products is included for comparison purposes.

\begin{tabular}{lcc}
\hline & $1970-2011$ & $1998-2011$ \\
\hline Natural Gas Share of PCE & $0.79 \%$ & $0.59 \%$ \\
Fuel Oil Share of PCE & $0.44 \%$ & $0.22 \%$ \\
Motor Vehicle Fuels Share of PCE & $3.18 \%$ & $2.88 \%$ \\
Electricity Share of PCE & $1.77 \%$ & $1.51 \%$ \\
\hline
\end{tabular}

Table 2: Share of Select Energy Sources in Personal Consumption Expenditures

In terms of direct spending on oil and natural gas, roughly $3 \%$ of consumer expenditures were used for motor fuels and $0.3 \%$ for fuel oil, while only about $0.6 \%$ were on natural gas. That is, spending directly on oil-related products was about five to six times greater than spending on natural gas. By comparison, electricity only accounted for about $1.6 \%$ of consumer expenditures, and natural gas only accounts for about a fifth of primary energy use in this sector.

We cannot conclude from Table 2 that changes in natural gas prices have little or no impact on consumer expenditures. But we can conclude that the impacts of such changes are likely to be smaller than for oil. This smaller share of expenditures on natural gas also indicates that there will be a smaller impact on savings for precautionary purposes when natural gas prices rise. It is unclear from this data how purchases of durable goods might change in response to variations in natural gas prices.

Taken together, the results in Tables 1 and 2 indicate that natural gas may be able to impact the production of various industrial sectors and well as consumer expenditures. However, the magnitude of such impacts is unclear, as is the ability of natural gas to impact overall economic activity in the U.S. We turn next to these questions.

\section{Quantitative Impacts}

In this section we use two different techniques to understand and quantify the impact of natural gas on U.S. economic activity. We first consider how real natural gas prices affect industrial production using Granger causality tests, in-line with an earlier literature on oil price shocks. This analysis includes both total industrial production and various sub-indices. Using such tests does not account for the fact that the real natural gas price and U.S. economic activity are jointly determined. To take account of this endogeneity we then estimate a VAR model and use different innovation accounting techniques to assess quantitative impacts.

\footnotetext{
${ }^{5}$ See the appendix for details on the calculations and data.
} 


\subsection{Natural Gas Prices and U.S. Industrial Production}

We begin by conducting an analysis similar to Kliesen (2006) and attempt to quantify the importance of changes in real natural gas prices for various industrial production indices. In this case total industrial production is used as a proxy for U.S. economic activity. The methods we use are based on the literature on oil price shocks and economic activity [see Hamilton (1996) and Hooker (1996) for notable examples], specifically the use of bivariate Granger causality tests as in Cunado and Perez de Gracia (2003).

The industrial production indices we use correspond to the sectors outlined in Table 1 and the real natural gas price is the real wellhead price of U.S. natural gas. ${ }^{6}$ The sample period ranges from 1993M01-2012M05. We choose this shorter period even though additional data is available because of major changes in the U.S. natural gas market during the 1980s related to deregulation. This deregulation process ended in 1992 with the implementation of FERC Order No. 636, which gave all natural gas sellers equal access for the movement of their gas, and so we take 1993 as our starting point.

Before conducting Granger causality tests we check the stationarity of the data. Table 5 (in the appendix) shows the results of two different unit root tests on the natural logarithm of each respective industrial production series and the real natural gas price from 1993M01-2012M05. Each of the series appear to have a unit root over the sample period. ${ }^{7}$ Given these results, we test for Granger causality from the logarithm of real natural gas prices $\left(r p g_{t}\right)$ to the logarithm of each industrial production index $\left(i p_{i, t}\right)$ using (Cunado and Perez de Gracia, 2003): ${ }^{8}$

$$
\Delta i p_{i, t}=\alpha_{0}+\sum_{j=1}^{k} \alpha_{1 j} \Delta i p_{i, t-j}+\sum_{j=1}^{k} \alpha_{2 j} \Delta r p g_{t-j}+\epsilon_{t}
$$

We test the hypothesis that $\alpha_{21}=\alpha_{22}=\ldots=\alpha_{2 k}=0$. The lag length $(k)$ is chosen using the modified Akaike criterion. Rejecting this hypothesis indicates that changes in natural gas prices Granger cause changes in the respective industrial production index. Table 3 reports the p-values from each test for each series. ${ }^{9}$

Consistent with the results in Kliesen (2006), we do not find that changes in natural gas prices play a statistically significant role in driving changes in total industrial production. With respect to the sub-indices our results differ from those of Kliesen (2006), who found that natural gas price changes were important only for furniture and related products, but not necessarily the other subindices. We find that changes in natural gas prices do Granger cause industrial production in nonmetallic mineral products, chemicals, and apparel and leather goods. ${ }^{10}$ The results also do not change substantially when alternative measures of natural gas price changes are used as in Cunado and Perez de Gracia (2003).

\footnotetext{
${ }^{6}$ See the appendix for full details on the data.

${ }^{7}$ The only questionable series is primary metals, where the ADF test cannot reject a unit root and the KPSS test cannot reject stationarity. Because the correlogram shows a slow decay for this series, we treat it as a unit root process as with the other industrial production indices.

${ }^{8}$ In unreported tests, we also find no evidence of cointegration between the real natural gas price and each industrial production index.

${ }^{9} \mathrm{p}$-values for the period 1980M01-2012M05 are reported in the appendix.

${ }^{10}$ Over the period 1980M01-2012M05 changes in natural gas prices do not Granger cause industrial production in apparel and leather goods.
} 


\begin{tabular}{lcc}
\hline & p-values & Lags \\
\hline Total Industrial Production & 0.720 & 4 \\
Nonmetallic Mineral Products & $0.004^{* * *}$ & 3 \\
Paper & 0.083 & 2 \\
Primary Metals & 0.237 & 2 \\
Food, Beverage, and Tobacco & 0.236 & 2 \\
Textiles and Products & 0.862 & 3 \\
Chemicals & $0.050^{* *}$ & 2 \\
Apparel and Leather Goods & $0.033^{* *}$ & 2 \\
Wood Products & 0.314 & 3 \\
Fabricated Metal Products & 0.771 & 3 \\
Printing and Related Activities & 0.791 & 2 \\
Plastics and Rubber Products & 0.494 & 3 \\
Petroleum and Coal Products & 0.585 & 2 \\
Furniture and Related Products & 0.361 & 3 \\
Electrical Equipment and Related & 0.223 & 4 \\
Machinery & 0.180 & 3 \\
Miscellaneous & 0.456 & 3 \\
Computer and Electronic Products & 0.656 & 2 \\
\hline
\end{tabular}

Table 3: p-values from various Granger causality tests for the period 1993M01-2012M05. Two asterisks indicate rejection at the $5 \%$ level and three indicates rejection at the $1 \%$ level.

The fact that variations in natural gas prices help to predict changes in chemicals and nonmetallic minerals production is consistent with its importance as a feedstock in these sectors. In particular, expenditures on natural gas accounted for almost $30 \%$ of gross output in the non-metallic minerals sector on average since 1998. Natural gas is also an important feedstock into the chemicals industry, where it accounted for almost 34\% of energy consumption in the 2006 MECS survey. It is unclear why the real natural gas price helps to predict industrial production in apparel and leather goods.

The results of this analysis indicate that natural gas does not have an important impact on overall U.S. economic activity or on most manufacturing industries, as proxied through total industrial production and sub-indices. However, these results should be interpreted with caution. While the analysis above is useful for assessing the relationship between natural gas prices and economic activity, there are problems in using changes in natural gas prices to assess the impact of the natural gas market on U.S. economic activity. We address these issues in the next section.

\section{$3.2 \quad$ Addressing Endogeneity}

A recurrent concern in the literature on oil prices and economic activity is that the exercise in the previous section does not take into account the fact that the natural gas price is jointly determined with measures of economic activity [see for example Barsky and Kilian (2004) and Arora and Gomis-Porqueras (2011)]. That is, while macroeconomic aggregates such as industrial production may change due to variations in natural gas prices, these aggregates can also alter the natural gas price itself. This reverse causality means that cause and effect are no longer well defined (Kilian, 2009). The implication is that the reason why the natural gas price changed in the first place is important in determining its impact.

For the test results above, this means that the natural gas prices are driven by different factors over the sample. Any changes in such prices cannot be separated from the underlying cause, which 
is not addressed in the Granger causality tests. A different way to look at the impact of natural gas on U.S. economic activity is first to understand why the natural gas price changes, and then to separate out which particular causes of natural gas price changes are most important for economic activity. Below we take such an approach by estimating a structural vector autoregression (VAR) in the spirit of Kilian (2009) and Kilian and Murphy (2012).

We begin by estimating a four-variable VAR that includes variables to characterize the supply, demand, and price of U.S. natural gas. This includes the supply of natural gas, its demand for use in the production of goods and services, natural gas demand for use in heating and power generation, and the real price of natural gas. We use a recursive identification scheme to construct a historical decomposition of the real natural gas price and also consider its impulse responses to our identified shocks. We conclude by estimating a slightly different VAR that includes total U.S. industrial production to assess the impact of each identified shock on U.S. economic activity.

\subsubsection{VAR Model}

A general VAR process can be encapsulated by a mean-zero moving average representation (without any deterministic terms):

$$
\mathbf{y}_{t}=\sum_{j=0}^{\infty} \mathbf{B}_{j} \mathbf{u}_{t-j}
$$

where $\mathbf{y}_{t}$ is an $N \times 1$ vector of variables, the $\mathbf{B}_{j}$ are $N \times N$ matrices of coefficients, and the reduced form errors $\left(\mathbf{u}_{t}\right)$ are $N \times 1$ white noise processes with $E\left(\mathbf{u}_{t}, \mathbf{u}_{t}^{\prime}\right)=\mathbf{S}_{u}$. The coefficient matrices $\left(\mathbf{B}_{j}\right)$ summarize the responses of the variables to the respective errors. Because $\mathbf{S}_{u}$ is not necessarily diagonal, the errors may be correlated across equations in the same time period. As is well-known, this can make interpretation of any responses misleading, because co-movement with other variables is not taken into account.

An equivalent representation of the moving average process with orthogonal innovations can circumvent this issue. In this case the transformed innovations will be uncorrelated by construction, so that the variance-covariance matrix of the shocks is diagonal. The identity matrix is often chosen in this case, which amounts to finding an $N \times N$ matrix $\mathbf{G}$ such that:

$$
\mathbf{G S}_{u} \mathbf{G}^{\prime}=\mathbf{I}
$$

where $\mathbf{I}$ is the $N \times N$ identity matrix. The orthogonal innovations are $\boldsymbol{\epsilon}_{t}=\mathbf{G u}_{t}$, so that $E\left(\boldsymbol{\epsilon}_{t}, \boldsymbol{\epsilon}_{t}^{\prime}\right)=$ $\mathbf{G} E\left(\mathbf{u}_{t}, \mathbf{u}_{t}^{\prime}\right) \mathbf{G}^{\prime}=\mathbf{I}$. These innovations are uncorrelated across both time and equations. In this case equation (2) can be rewritten:

$$
\mathbf{y}_{t}=\sum_{j=0}^{\infty} \mathbf{B}_{j} \mathbf{G} \boldsymbol{\epsilon}_{t-j}
$$

In this equation the $\mathbf{B}_{j} \mathbf{G}$ summarize the impulse responses which are plotted below. Also used in subsequent analysis to summarize model results are historical decompositions and forecast error variance decompositions. Historical decompositions divide the responsibility for differences between 
actual historical values at any time $t+i$ between a base projection made at $t$ and the different model innovations between $t$ and $t+i$. The importance of any innovation after $T$ can be gauged by seeing how it closes the gap between the base projection and the actual historical value (Burbridge and Harrison, 1985). This is easier to see if the general VAR process in equation (2) at $t+i$ is divided into two parts:

$$
\mathbf{y}_{t+i}=\sum_{j=0}^{i-1} \mathbf{B}_{j} \mathbf{G} \boldsymbol{\epsilon}_{t+i-j}+\sum_{j=i}^{\infty} \mathbf{B}_{j} \mathbf{G} \boldsymbol{\epsilon}_{t+i-j}
$$

The first term on the right-hand side is the part of the actual value attributable to the shocks since $t$, and the second is the base projection at $t$.

The forecast error variance decomposition can be reconstructed by recognizing that $\sum_{j=i}^{\infty} \mathbf{B}_{j} \mathbf{G} \boldsymbol{\epsilon}_{t+i-j}=$ $E_{t} \mathbf{y}_{t+i}$, so that the error of the i-step ahead forecast is:

$$
\mathbf{y}_{t+i}-E_{t} \mathbf{y}_{t+i}=\sum_{j=0}^{i-1} \mathbf{B}_{j} \mathbf{G} \boldsymbol{\epsilon}_{t+i-j}
$$

From this equation we can extract the total variance in the i-step ahead forecast error of variable $j$, as well as the variance in the error of variable $j$ due to variable $k$. The variance decompositions are reported as the fraction of the error variance in $j$ due to $k$, so that the sum over all $k$ is one. Below $i$ values of one month, four months, and one year are used.

\subsubsection{Identification}

Our model contains the natural logarithm of series which range from 1993M01-2012M05 and encompass the supply, demand, and price of U.S. natural gas. ${ }^{11}$ The first variable is the change in U.S. natural gas production $(\Delta n g)$. This series is broad enough to encompass changes in total U.S. natural gas production over the sample period. We use marketed instead of gross production to exclude any gas which is used in extraction or in processing operations.

Figure 1 shows that U.S. demand for natural gas can be divided between four end-use sectors. Within these sectors the demand can be further categorized as for direct use in production, for heating, or for generating power. The second variable in our VAR $(g d s)$ captures this production demand for natural gas. We use U.S. consumption of natural gas in the industrial sector excluding combined heat and power. This variable is replaced by total U.S. industrial production (ipd) in subsequent analysis to incorporate a direct measure of economic activity. In this case we use ipd as a proxy for natural gas demand in production, instead of a direct measure when $g d s$ is used.

We call the remaining natural gas demand for use in heating or power generation energy demand (ecs) and make it the third variable in our VAR. This is the sum of U.S. natural gas consumption in residential, commercial, transportation, and electric end-use sectors and industrial consumption for combined heat and power. The final variable in the model is the real U.S. wellhead price of natural gas $(r p g)$. The wellhead price is used instead of a more familiar marker such as Henry Hub because it has a longer history.

\footnotetext{
${ }^{11}$ See the appendix for full details on the data.
} 
Given these variables and consistent with the notation above, we decompose the errors and identify the shocks in the model as:

$$
\mathbf{u}_{t} \equiv\left(\begin{array}{l}
u_{t}^{\Delta n g} \\
u_{t}^{g d s} \\
u_{t}^{e c s} \\
u_{t}^{r p g}
\end{array}\right)=\left[\begin{array}{cccc}
g_{11} & 0 & 0 & 0 \\
g_{21} & g_{22} & 0 & 0 \\
g_{31} & g_{32} & g_{33} & 0 \\
g_{41} & g_{42} & g_{43} & g_{44}
\end{array}\right]\left(\begin{array}{l}
\epsilon^{\text {supply shock }} \\
\epsilon^{\text {goods demand shock }} \\
\epsilon^{\text {energy demand shock }} \\
\epsilon^{\text {other ng shock }}
\end{array}\right)
$$

The first shock is an innovation to U.S. natural gas supply. We assume that such unexpected changes can impact each of the variables in the model during the current month. This ordering also implies that natural gas supply does not respond to any of the remaining shocks in the current month. This reflects the costs and difficulties of changing natural gas production quickly. An example of a supply shock is the supply disruption in the aftermath of Hurricane Katrina.

The second shock captures unexpected changes in demand for natural gas due to the production of goods. This can include variations in economic activity and also technical change in the use of natural gas in production. This shock can impact natural gas demand for heating and power and the real natural gas price in the current month, but is unable to impact natural gas supply during that period. We assume the latter two variables can be affected in the current month because changes in economic activity impact the demand for both heating and power in the current month, as business establishments will likely demand more heat and power (for example moving from two to three shifts in a factory). The reverse is true in a downturn. Economic activity should also impact the real natural gas price in the current month given the daily trading in energy markets.

The shocks which capture unexpected movements in natural gas demand for use in heating and power generation are ordered third, and labeled energy demand shocks. Such innovations are able to vary the real natural gas price in the current period as well as heating and power demand, but have no impact on natural gas demand for goods production or natural gas supply in the current month. This shock captures unexpected variations in the weather which can change natural gas demand, or unpredictable switching of electric utilities from one energy source to another.

The final shock captures the impact of other demand or non-demand factors on the real natural gas price. This includes the demand for natural gas for storage, whether for speculative or precautionary purposes. It also includes the impact of movements in the oil price on natural gas prices. There is evidence that these two variables have a time-varying relationship, and when they do move together the natural gas price tends to follow the oil price (Ramberg and Parsons, 2012). These other innovations cannot change either natural gas supply or demand in the current month by assumption.

\subsubsection{Historical Decomposition of the Real Natural Gas Price}

We begin by looking at the factors which have driven the real price of natural gas over time using historical decompositions. Figure 2 shows the cumulative effect of each respective shock on the real natural gas price over the period from 1993M01-2012M05. The top-left panel of Figure 2 shows that until about 2003, unexpected movements in natural gas supply played a small (mostly negative) role in accounting for the real natural gas price. The supply shocks became much more important after 2003, rising quickly until a peak was reached in late-2005. This peak was likely due to the 
production disruptions following Hurricane Katrina. The contributions of the supply shock then gradually decline, eventually moving negative in 2011.

These relatively large rises and declines in the importance of supply shocks to the real natural gas price are easier to understand when looking at U.S. natural gas supply. Figure 3 compares the cumulative contribution of the natural gas supply shock from the top-left panel of Figure 2 to annual percent changes in U.S. natural gas production. The contribution of the supply shock to the real natural gas price begins to increase sometime in 2001, just after the growth rate in natural gas supply begins to decline. This supply decline continues until 2006, as does the importance of supply shocks. And the contribution of supply shocks begins to fall in 2006 as the growth rate of production increases. There seems to a clear link after 2000 between the importance of supply shocks for the real natural gas price and changes in U.S. natural gas supply.

The top-right panel of Figure 2 shows that innovations to natural gas demand have played a relatively small role historically in accounting for the real natural gas price. The value of these goods demand shocks fluctuates consistently between $-\$ 0.50$ and $\$ 0.50$. Especially surprising is the relatively small role such shocks play after 2005. Kilian (2009) shows that demand shocks were the most important contributors to the oil price post-2005.

The bottom-left panel of Figure 2 shows that unexpected movements in natural gas demand for use in heating and power have also played a modest role in accounting for real natural gas prices since 1993. As would be expected, such demand was an important contributor to the price around the turn of the century due to deregulation in electricity markets. And there were rises in the contribution of energy demand shocks during the cold winter of 2003, as well as due to Hurricane Katrina in late-2005. However, the magnitude has been relatively small compared to supply and other shocks.

The bottom-right panel of Figure 2 shows the importance of other factors in driving the real natural gas price. In the 1990's such factors contributed both positively and negatively to the price. After 2000 these other shocks have mainly made a positive contribution to the real natural gas price, culminating with a spike in 2008. This likely reflects the influence of oil prices on the real natural gas price. These other shocks also did play a role in the natural gas price rise in late-2005, probably related to inventory demand after Hurricane Katrina.

The historical decompositions lead to two conclusions. The first is that the factors driving the real natural gas price vary over time. The second point is that supply and other shocks have contributed more to the price in terms of magnitude then goods or energy demand shocks, especially post-2000.

\subsubsection{Impulse Responses of the Real Natural Gas Price}

The historical decompositions provide some insight into the dynamics driving the real natural gas price over time. The impulse responses in Figure 4 show the instantaneous and continuing impacts of a one standard deviation rise in each shock to the real natural gas price.

The top-left panel of Figure 4 highlights the immediate fall in real natural gas prices following a rise in the growth rate of natural gas production. This fall continues indefinitely, but is statistically significant for only about five months. The top-right panel of Figure 4 shows that the real natural gas price increases with rising demand for natural gas for use in goods production. This response 
is mainly positive, but may or may not be statistically significant.

The impulse response in the bottom-left panel of Figure 4 does display a statistically significant rise in the real natural gas price. This indicates that increased demand of natural gas for heating and power does result in a higher price over the sample period. The final response is in the bottomright panel of Figure 4. Real natural gas prices jump immediately following an unexpected rise in the other natural gas shock. This is easily the largest response of the four, and indicates the importance of the oil price and inventories in movements of the real natural gas price.

We conclude from the impulse responses that a rise in any of the shocks can have an impact on the real natural gas price. However, only the supply and other shocks lead to an instantaneous impact on this price. In the case of the other shock, the price immediately jumps over $9 \%$, while the supply shock leads to an instantaneous fall in the price of over $2 \%$.

\subsubsection{Impacts on Industrial Production}

In order to evaluate the impact of natural gas on U.S. economic activity we re-estimate the fourvariable VAR using industrial production $(i p d)$ in place natural gas demand for use in goods production $(g d s)$. As outlined above, our interpretation of the shocks does not change in this case, we are just using a proxy for natural gas production demand instead of a direct measure. Figure 5 shows impulses responses from this estimation with the same ordering of variables and interpretation of shocks.

The top row of Figure 5 shows that unexpected increases in natural gas supply or natural gas demand for goods production result in higher industrial production. The instantaneous increase due to a supply shock is likely the result of both lower prices and the benefits of increasing production. This statistically significant response shows that the natural gas market does in fact impact total industrial production in contrast to the Granger causality results shown above. Industrial production also rises with positive shocks to goods production demand, as would be expected. The bottom row of Figure 5 shows that industrial production does not respond in a statistically significant manner to either energy demand or other natural gas shocks.

Another way to assess the impact of each shock is by calculating the fraction of the forecast error variance accounted for by each of the shocks, as shown in Table 4.

\begin{tabular}{lccc}
\hline Shock & $1 \mathrm{M}$ & $4 \mathrm{M}$ & $1 \mathrm{Y}$ \\
\hline Supply Shock & 9.5 & 2.0 & 0.6 \\
Goods Demand Shock & 90.5 & 97.9 & 96.4 \\
Energy Demand Shock & 0.0 & 0.1 & 0.4 \\
Other NG Shock & 0.0 & 0.0 & 2.6 \\
\hline
\end{tabular}

Table 4: Percent of horizon step ahead forecast error variance of industrial production accounted for by the listed shocks.

The variance decompositions reinforce the results of each respective impulse response. Over the first four months, both supply and goods demand shocks account for all of the variance in the forecast error, indicating a very small role for the other two shocks. As with the impulse responses, the impact of a supply shock is felt quickly and then dissipates. At one year the other natural gas shock does account for nearly three percent of the variance in the forecast error, but this is dwarfed 
by the contribution of the goods demand shock.

Taken together, the impulse responses and variance decomposition imply that the supply of natural gas and demand for use in production are the two primary channels by which natural gas affects economic activity. In contrast, neither energy demand or other shocks seem to have an impact on economic activity.

\subsubsection{Summary of VAR Results}

In contrast to the Granger causality tests reported above and in Kliesen (2006), our VAR shows that the natural gas market does impact U.S. economic activity. The primary channel for this affect is through variations in natural gas supply. Impulse responses show that positive shocks to natural gas supply lead to an instantaneous rise in U.S. economic activity that falls off over time.

Our historical decompositions also show that different shocks have contributed to changes in real natural gas prices over time. But after 2000, both supply and other shocks have become more important in accounting for variations in the real natural gas price. And the impulse responses of the real natural gas price show that both the supply and other shocks lead to immediate changes in the natural gas price, while the other shocks take longer to have an impact.

The VAR can also explain why the Granger causality tests above show small impacts of natural gas on U.S. economic activity. The other shocks are the most important in the dynamics of the real natural gas price, as shown in the historical decompositions and impulse responses. However, industrial production does not respond to these other shocks. Thus the shocks which have the largest impact on the real natural gas price (other shocks) have little or no impact on industrial production. This makes it difficult to use the price as a proxy for the entire natural gas market.

\section{Conclusion}

Our analysis shows that the natural gas market has historically impacted U.S. economic activity through natural gas supply. In terms of point estimates, the VAR results show that a $1 \%$ increase in natural gas production leads to an immediate $0.1 \%$ rise in U.S. industrial production. The average monthly increase (from the same month in the previous year) in marketed U.S. natural gas production has been $0.6 \%$ since $1976,1.5 \%$ since $1993,3.5 \%$ since 2005 , and $4.3 \%$ since 2007 . Within a plausible range of natural gas production estimates, our results indicate that increases in natural gas supply alone might raise monthly industrial production by 0.1 to 0.5 percent.

These impacts could be much larger depending on how different sectors of the economy respond to abundant U.S. natural gas supply. For example, various firms have announced plans to build chemical plants close to U.S. natural gas resources due to lower prices. Electrical utilities have

and will continue to switch from traditional coal-based power generation to natural gas-based generation. And there may even be opportunities in the longer-term for greater movement away from petroleum-based vehicle engines to those which run on natural gas.

It is very likely that this additional demand will lead to higher U.S. natural gas prices. But our analysis shows that the impact of natural gas on U.S. economic activity works primarily through supply, and has not historically responded in a statistically significant way to industrial or energy demand. To the extent that this additional demand leads to greater production of natural gas, our 
model predicts a net benefit for the U.S. economy even with higher prices.

\section{References}

Arora, Vipin and Pedro Gomis-Porqueras, "Oil Price Dynamics in a Real Business Cycle Model," Working Paper 2011-17, CAMA 2011.

Barsky, Robert B. and Lutz Kilian, "Oil and the Macroeconomy Since the 1970s," Journal of Economic Perspectives, 2004, 18 (4), 115-134.

Burbridge, John and Alan Harrison, "A Historical Decomposition of the Great Depression to Determine the Role of Money," Journal of Monetary Economics, 1985, 16, 45-54.

Cunado, Juncal and Fernando Perez de Gracia, "Do Oil Price Shocks Matter? Evidence for Some European Countries," Energy Economics, 2003, 25, 137-154.

Hamilton, James D., "This is What Happended to the Oil Price-Macroeconomy Relationship," Journal of Monetary Economics, 1996, 38, 215-220.

Hooker, M.A., "What Happened to the Oil Price-Macroeconomy Relationship?," Journal of Monetary Economics, 1996, 38, 195-213.

Kilian, Lutz, "The Economic Effects of Energy Price Shocks," Journal of Economic Literature, 2008, $46(4), 871-909$.

_ , "Not All Oil Price Shocks are Alike: Disentangling Demand and Supply Shocks in the Crude Oil Market," American Economic Review, 2009, 99 (3), 1053-1069.

- and Dan Murphy, "The Role of Inventories and Speculative Trading in the Global Market for Crude Oil," Mimeo 2012.

Kliesen, Kevin L., "Rising Natural Gas Prices and Real Economic Activity," Federal Reserve Bank of St. Louis Review, 2006, 88 (6), 511-526.

Ramberg, David J. and John E. Parsons, "The Weak Tie Between Natural Gas and Oil Prices," The Energy Journal, 2012, 33 (2), 13-35.

\section{Data}

Each of the respective industrial production indices are taken from the Board of Governors of the Federal Reserve, and are available at http://www . federalreserve.gov/releases/g17/download. htm at a monthly frequency from 1967 onwards. The specific indices chosen correspond to those with a three digit NAICS code in the manufacturing sector (NAICS 31-33), with the exception of the total industrial production index. The total index includes manufacturing, mining, and utilities.

The industry share of gross output is calculated by dividing the nominal amount spent on natural gas distribution by each respective industry by nominal gross output in that industry. Spending on 
natural gas distribution comes from the BEA's KLEMS Intermediate Use Estimates, which can be found at http://www. bea.gov/industry/more.htm. These are available annually from 1998-2010. Gross output for each three digit manufacturing industry comes from the GDP-by-Industry data of the BEA and can be found at http://www.bea.gov/industry/gdpbyind_data.htm. These values are available annually from 1998-2011.

The share of industry gross output in domestic gross output is the ratio of these two numbers and is also taken from the BEA's GDP-by-Industry data, which are available annually from 1998-2011. The share of natural gas used as a fraction of total energy consumption is calculated based on the 2006 Manufacturing Energy Consumption Survey from the EIA. The data is taken from Table 1.2 of this survey, which is available at http://www.eia.gov/emeu/mecs/mecs2006/2006tables.html. Data on the share of personal consumption expenditures spent on select energy goods comes from the BEA. Specifically, the shares are derived from Table 2.5.5 of the National Income and Product Accounts (NIPA), which are available at http://www.bea.gov/national/index.htm\#gdp at an annual frequency.

Data on natural gas production, the real natural gas price, and end-use consumption of natural gas are taken from the EIA. Natural gas production is marketed U.S. natural gas withdrawals in millions of cubic feet, and is available at a monthly frequency from 1980M01 at http://www.eia. gov/dnav/ng/hist/n9010us2m.htm. The real natural gas price is the U.S. natural gas wellhead price deflated by the U.S. consumer price index (CPI) for all urban consumers. The wellhead price is available at a monthly frequency from 1976M01 and comes from http://www.eia.gov/ dnav/ng/hist/n9190us3m.htm. The CPI is also available monthly from 1947M01 and is taken from the Federal Reserve Bank of St. Louis's Federal Reserve Economic Data (FRED) at http: //research.stlouisfed.org/fred2/series/CPIAUCSL/downloaddata?cid=9.

End-use consumption of natural gas is available from the EIA's monthly energy review. Data on consumption of natural gas by end-use sector is available in Table 4.1 of this document, and the monthly historical data can be found at http://www.eia.gov/totalenergy/data/monthly/ \#naturalgas in billions of cubic feet. In calculating the natural gas demand for use in goods production we use U.S. consumption of natural gas in the industrial sector excluding combined heat and power. To get natural gas demand for use as energy, we take the sum of natural gas consumed in the residential, commercial, transportation, and electric end-use sectors and industrial consumption for combined heat and power.

\section{Tables and Figures}




\begin{tabular}{lcc}
\hline & ADF & KPSS \\
\hline Real Natural Gas Price & 2.61 & $1.05^{* * *}$ \\
Total Industrial Production & 1.20 & $2.61^{* * *}$ \\
Nonmetallic Mineral Products & 1.88 & $1.20^{* * *}$ \\
Paper & 1.84 & $1.21^{* * *}$ \\
Primary Metals & 2.53 & 0.22 \\
Food, Beverage, and Tobacco & 2.23 & $2.57^{* * *}$ \\
Textiles and Products & 0.28 & $0.74^{* *}$ \\
Chemicals & 1.71 & $2.57^{* * *}$ \\
Apparel and Leather Goods & 1.00 & $1.99^{* * *}$ \\
Wood Products & 1.53 & $1.27^{* * *}$ \\
Fabricated Metal Products & 1.36 & $2.08^{* * *}$ \\
Printing and Related Activities & 2.40 & $1.48^{* * *}$ \\
Plastics and Rubber Products & 2.34 & $2.36^{* * *}$ \\
Petroleum and Coal Products & 1.01 & $2.01^{* * *}$ \\
Furniture and Related Products & 2.19 & $1.51^{* * *}$ \\
Electrical Equipment and Related & 1.75 & $1.33^{* * *}$ \\
Machinery & 1.56 & $1.87^{* * *}$ \\
Miscellaneous & 0.60 & $2.66^{* * *}$ \\
Computer and Electronic Products & 1.47 & $2.65^{* * *}$ \\
\hline
\end{tabular}

Table 5: Unit root test statistics for various series. The Augmented Dickey Fuller (ADF) test takes the presence of a unit root as the null hypothesis, and the KPSS test takes stationarity as the null hypothesis. Both tests use an intercept with no deterministic trend. Two asterisks indicate rejection at the $5 \%$ level and three indicates rejection at the $1 \%$ level.

\begin{tabular}{lcccc}
\hline & 1980M01-2012M05 & Lags & 1993M01-2012M05 & Lags \\
\hline Total Industrial Production & 0.756 & 3 & 0.720 & 4 \\
Nonmetallic Mineral Products & $0.032^{* *}$ & 3 & $0.004^{* * *}$ & 3 \\
Paper & 0.108 & 3 & 0.083 & 2 \\
Primary Metals & 0.787 & 2 & 0.237 & 2 \\
Food, Beverage, and Tobacco & 0.830 & 2 & 0.236 & 2 \\
Textiles and Products & 0.537 & 11 & 0.862 & 3 \\
Chemicals & $0.010^{* * *}$ & 4 & $0.050^{* *}$ & 2 \\
Apparel and Leather Goods & 0.090 & 4 & $0.033^{* *}$ & 2 \\
Wood Products & 0.847 & 3 & 0.314 & 3 \\
Fabricated Metal Products & 0.888 & 4 & 0.771 & 3 \\
Printing and Related Activities & 0.517 & 4 & 0.791 & 2 \\
Plastics and Rubber Products & 0.928 & 3 & 0.494 & 3 \\
Petroleum and Coal Products & 0.861 & 2 & 0.585 & 2 \\
Furniture and Related Products & 0.302 & 3 & 0.361 & 3 \\
Electrical Equipment and Related & 0.646 & 4 & 0.223 & 4 \\
Machinery & 0.621 & 3 & 0.180 & 3 \\
Miscellaneous & 0.338 & 3 & 0.456 & 3 \\
Computer and Electronic Products & 0.998 & 4 & 0.656 & 2 \\
\hline
\end{tabular}

Table 6: p-values from Granger causality tests for various periods. Lags determined using modified AIC. Two asterisks indicate rejection at the $5 \%$ level and three indicates rejection at the $1 \%$ level. 
Source

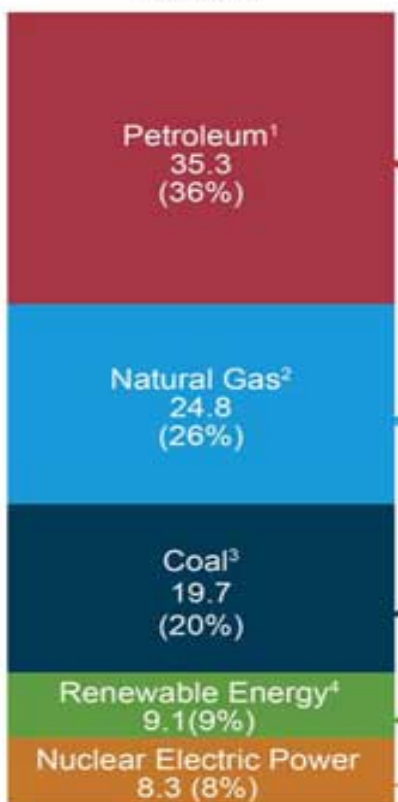

Sector

Percent of Sources

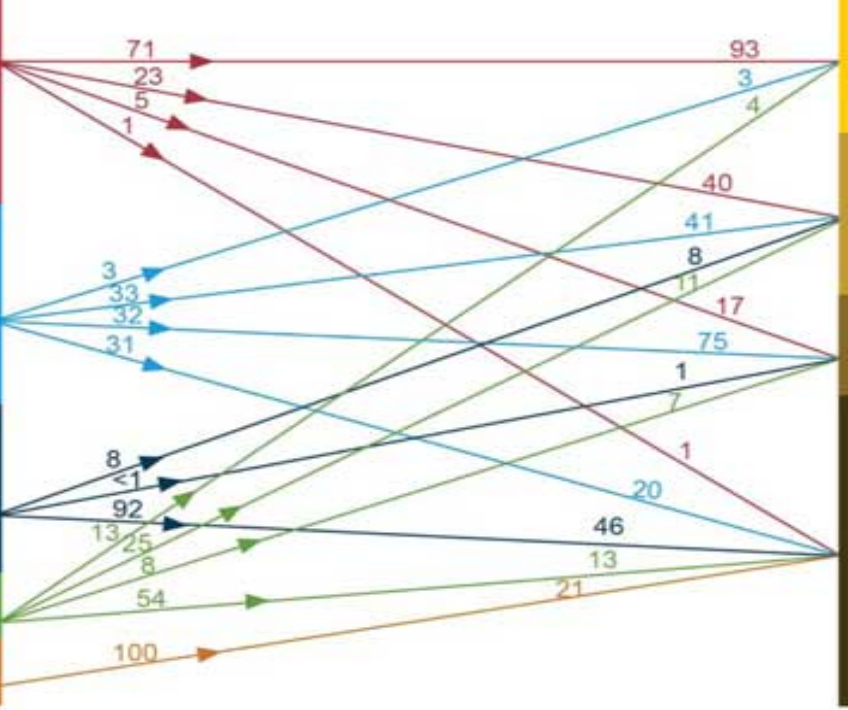

Transportation

27.0

$(28 \%)$

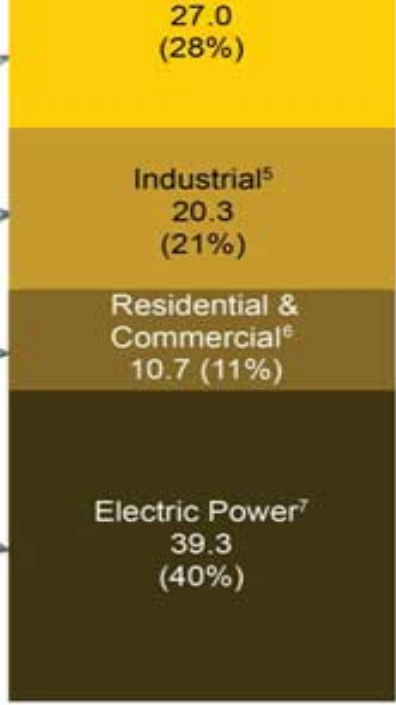

Figure 1: U.S. primary energy consumption by source and sector in quadrillion BTU. Reproduced from Figure 2.0 of the U.S. Energy Information Administration's Annual Energy Review 2011.

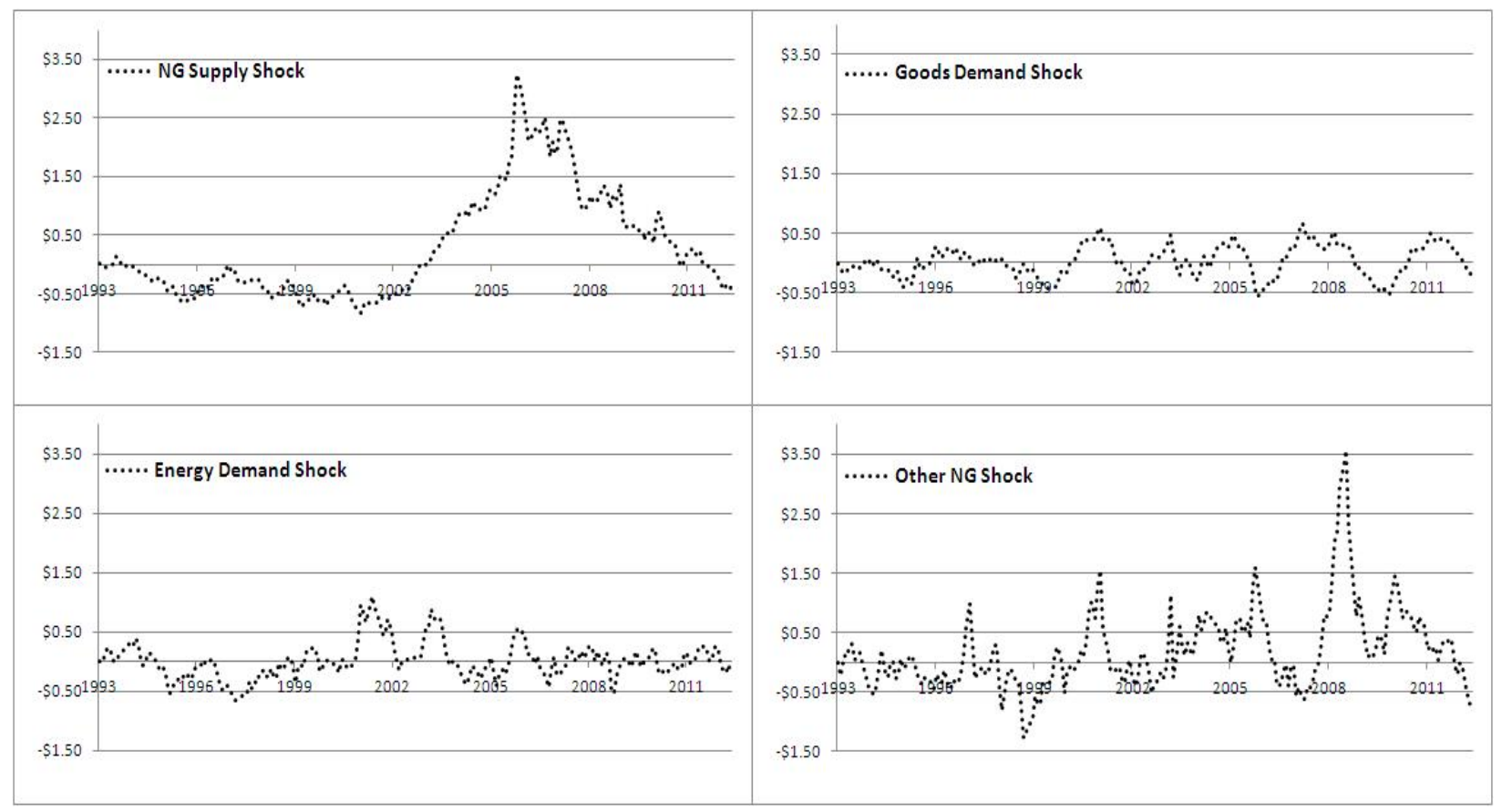

Figure 2: Historical decompositions of the real natural gas price without base projection. Based on four-variable VAR, 1993M01-2012M05. 


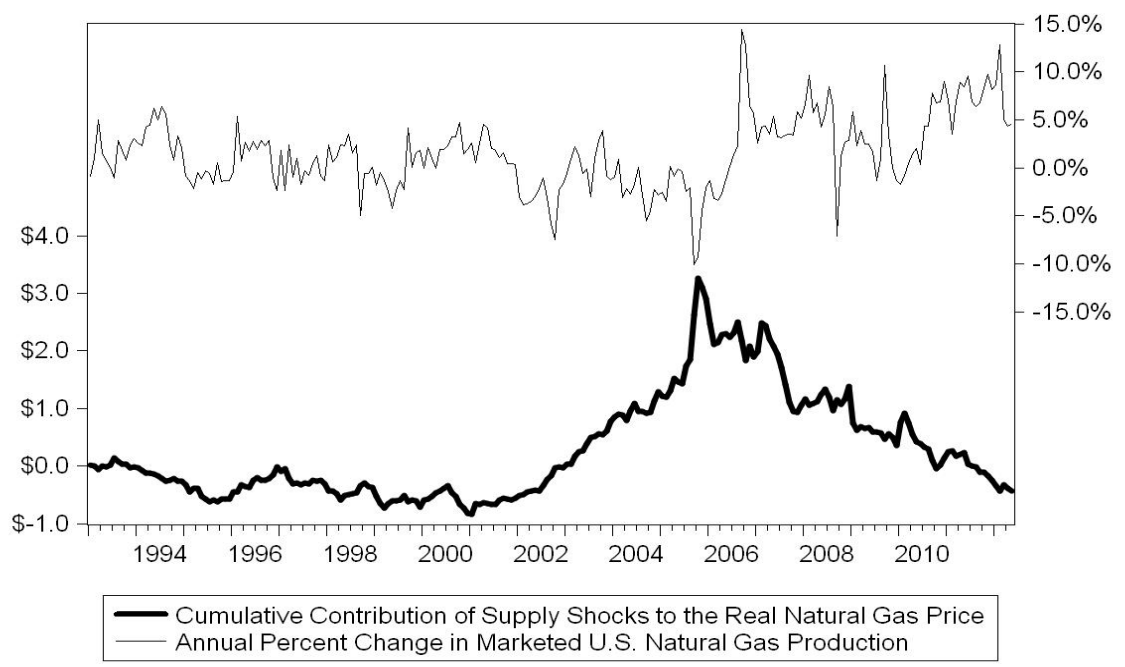

Figure 3: Cumulative contribution of supply shocks to the real natural gas price and annual percent changes in marketed U.S. natural gas production. Based on four-variable VAR, 1993M01-2012M05.
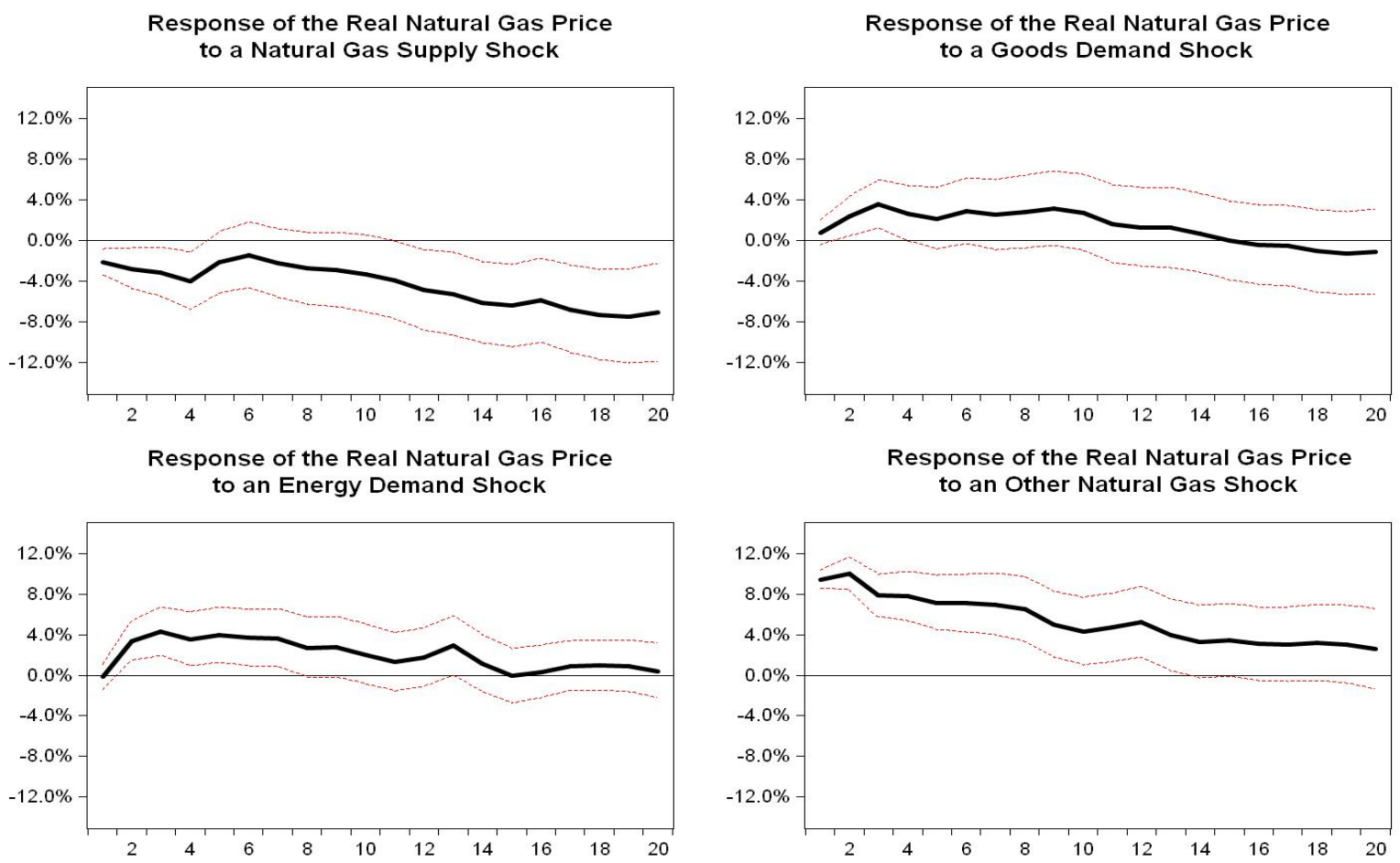

Figure 4: Impulse responses of the real natural gas price to shocks from the four-variable VAR. 

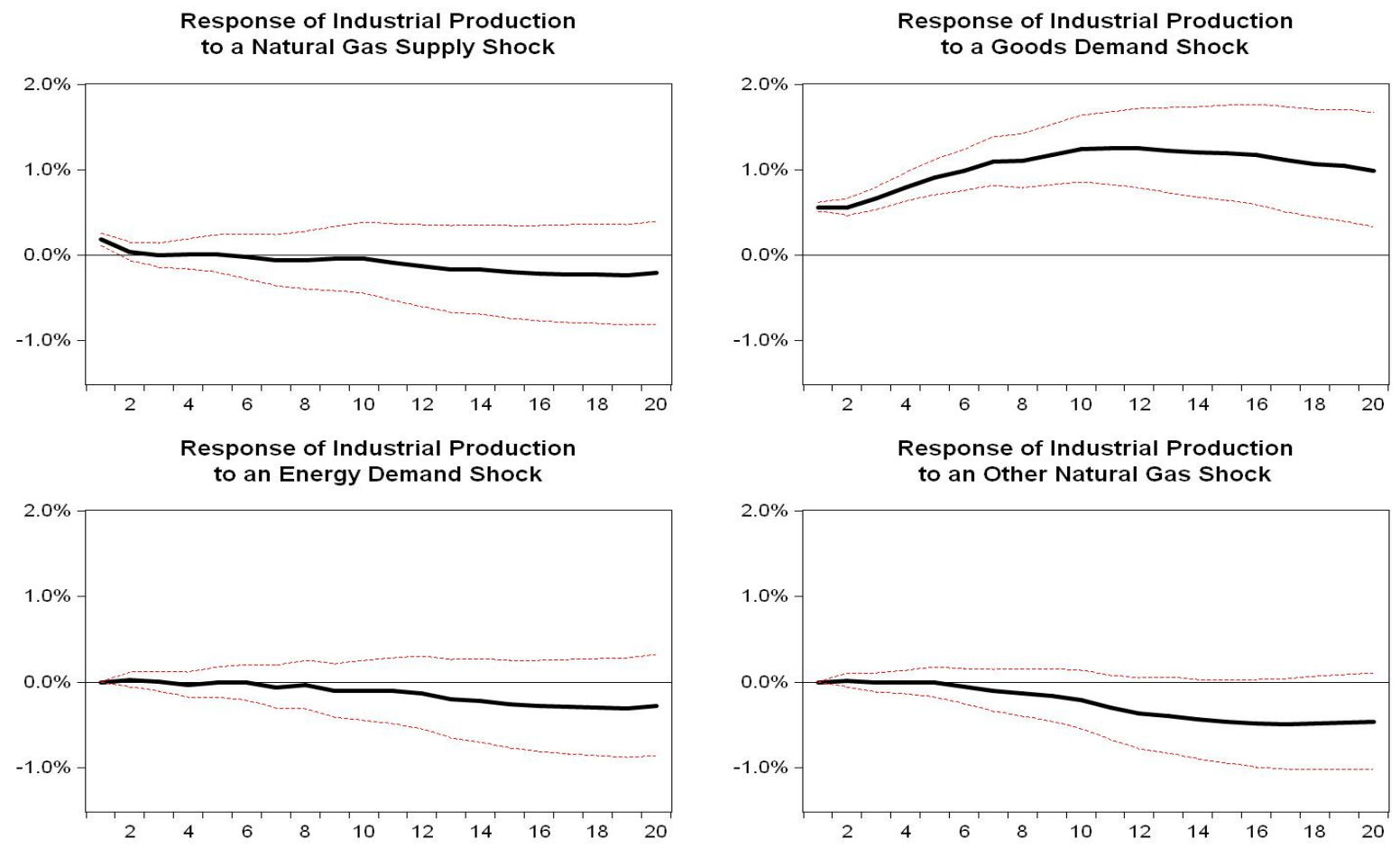

Figure 5: Impulse responses of industrial production to shocks from the four-variable VAR. 